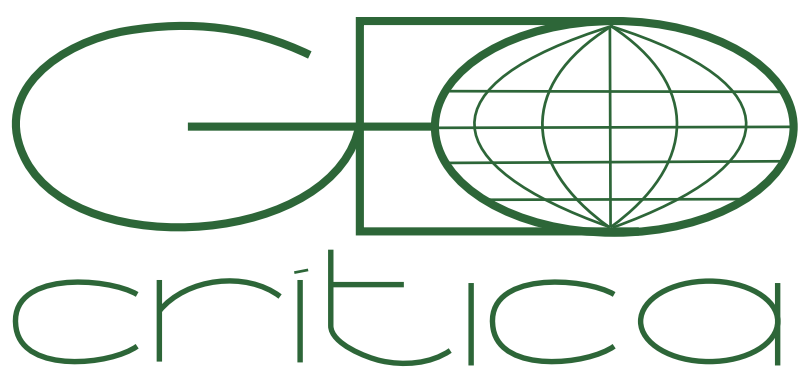

\section{Scripta Nova}

Revista Electrónica de Geografía y Ciencias Sociales Universitat de Barcelona

ISSN: $1138-97$

Vol. 25, Núm. 4 (2021), p. 29-50

\title{
CONTRIBUIÇÕES DA COLONILIADADE DO PODER, DO SABER, DO SER E DO TRABALHO NO ENTENDIMENTO DA ESCRAVIDÃO CONTEMPORÂNEO NA REGIÃO CENTRO-SUL DO PARANÁ
}

\author{
Adriano Makux de Paula \\ Universidade Federal do Paraná \\ adrianomakux@hotmail.com
}

Recibido: 18 febrero 2021; Devuelto para correcciones: 14 de junio 2021; Aceptado: 22 octubre 2021

\begin{abstract}
Contribuições da coloniliadade do poder, do saber, do ser e do trabalho no entendimento da escravidão contemporâneo na Região Centro-Sul do Paraná (Resumo)

O Estado do Paraná não está fora do círculo da violenta exploração que o trabalho escravo contemporâneo representa. Entre 2005 e 2017, foram resgatados 1.174 trabalhadores, segundo o Radar SIT, da Secretaria de Inspeção do Trabalho. Desses, 339 foram em atividades urbanas e 835 em atividades ligadas ao rural (RADAR SIT, 2019). O objetivo deste texto é apontar as vias de compreensão sobre a escravidão contemporânea na região Centro-Sul do Paraná, a partir da teoria da colonialidade. $\mathrm{O}$ artigo está dividido em duas partes: primeiro, apresentamos dados relativos ao trabalho escravo contemporâneo na Região Centro-Sul do Paraná e, segundo, debatemos o que ele representa, sob a perspectiva da teoria da colonialidade. Um dos resultados desse texto é mostrar como o racismo, implantado na América Latina pelo colonialismo, é uma estrutura de poder importante para compreender as razões de existir, em pleno século XXI, formas de exploração do trabalho características da escravidão. Portanto, concluímos que as análises sobre essa questão, que não levam em conta esses aspectos, só podem compreender parcialmente o problema da escravidão contemporânea.
\end{abstract}

Palavras-chave: Colonialidade, Exploração, Modernidade, Trabalho Escravo

Contributions of the Coloniality of Power, Knowledge, Being and Labor to the understanding of contemporary slavery in the Center South Region of Paraná (Abstract)

The State of Paraná is not outside the circle of violent exploitation that represents contemporary slave labor. Between 2005 and 2017, 1,174 workers were rescued, according to the SIT Radar of the Labor Inspection Secretary. Of these, 339 were in urban activities and 835 in activities related to the rural (RADAR SIT, 2019. In this sense, the purpose of this article is to point out ways of understanding contemporary slavery in the Center-South region of Paraná from the theory of coloniality. One of the results of the text is to show how racism, implanted in Latin America by colonialism, is an important power structure to understand the reasons for existing, in the 21st century, the forms of exploitation of labor characteristic of slavery. Therefore, we conclude that analyzes on this issue, which do not take these aspects into account, can only partially understand the problem of contemporary slavery.

Key words: Coloniality, Exploration, Modernity, slavery work. 
No Brasil a legislação que trata da escravidão contemporânea está baseada no Art. 149 do Código Penal. Ela determina as condições para sua caracterização: trabalhos forçados ou jornada exaustiva, condições degradantes de trabalho, restrição de liberdade por dívida ou impossibilidade de locomoção. De 1995 a 2020 foram mais de 54 mil trabalhadores resgatados da condição de escravidão contemporânea. O estado do Paraná registrou 1.174 homens e mulheres submetidos às configurações mais violentas de exploração do trabalho. E, mesmo depois de 24 anos do início das operações, o Grupos Especiais de Fiscalização Móveis (GEFMs) continuam a encontrar, ano após ano, sujeitos reduzidos às piores situações de degradância e dominação. Por que, mesmo depois de tanto tempo, esse processo persiste? Pensamos que a analisar essas questões levando em conta as várias faces da colonialidade (Quijano, 2007) pode trazer grandes contribuições para compreensão dessa problemática, sendo esse o objetivo deste artigo. Para realizar essa análise, optamos por um recorte espacial específico, que será chamado de círculo da escravidão contemporânea na região Centro-Sul do Paraná, compreendendo os municípios da região Centro-Sul e Sudeste do Paraná que tiveram trabalhadores resgatados.

A colonialidade é objetiva e subjetiva, como afirma Quijano (2014). Ela envolve o controle do trabalho, do sexo, da natureza e da cultura (poder). Igualmente, está relacionada ao saber na medida em que determinados conhecimentos e práticas dos dominantes são válidos, enquanto dos dominados, inválidos e primitivos. Também abarca fortemente a forma subjetiva de ser e "viver" no espaço e no tempo, segundo lógicas impostas da modernidade (ser). (Maldonado-Torres 2017). Portanto, oferece instrumentos poderosos para compreensão da realidade social do espaço latinoamericano.

A metodologia é qualitativa e está baseada nos seguintes procedimentos: primeiro, buscamos fazer um levantamento bibliográfico sobre os temas relevantes, a fim de entender o problema de pesquisa; segundo, pesquisamos dados secundários no Radar da Secretaria de Inspeção do Trabalho- Radar SIT, no Observatório da Erradicação do Trabalho Escravo e Tráfico de Pessoas, no Instituto Brasileiro de Geografia e Estatística IBGE; terceiro, realizamos uma análise documental com a revisão de 74 relatórios de fiscalização dos GEMF e de denúncia do Ministério Público do Trabalho; na quarta etapa, fizemos trabalhos de campo, nos municípios de Guarapuava-PR e Pinhão-PR, onde realizamos, por meio de questões semiabertas, entrevistas com 3 trabalhadores que passaram por situações laborais caracterizadas como escravidão contemporânea. É importante afirmar que o texto é resultado de uma pesquisa de doutorado em Geografia, ainda em andamento.

Dessa forma, o artigo está dividido em duas partes: na primeira, apresentamos dados sobre os resgates no círculo do trabalho escravo contemporâneo na região CentroSul do Paraná; na segunda, debatemos o que ele representa na perspectiva da teoria da colonialidade e como ela pode ajudar na melhor compreensão da continuidade desse problema social no Brasil. 


\section{Alguns aspectos da escravidão contemporânea no Paraná e na sua região Centro-Sul}

Neste trabalho vamos adotar o conceito de escravidão contemporânea. Ele tem sido empregado para reforçar que a escravidão faz parte do atual estágio da civilização moderna/colonial capitalista. Apesar de ter diferenças com a forma desenvolvida no colonialismo, ela reforça que a elite continua a empregar métodos coercitivos, violentos e desumanos na superexploração do trabalho de uma determinada camada da população (Figueira 2004). A legislação no Brasil tem empregado o conceito de "trabalho análogo à escravidão" ou "situação análoga à escravidão". Os fundamentos desse conceito são da ordem legal. A lei proíbe que uma pessoa seja escravizada por outra desde a abolição da escravidão em 1888 e, portanto, o que de fato existe é uma relação análoga e/ou similar (Nascimento 2012). Entretanto, na nossa visão, essa escolha tira potência explicativa e política da questão da escravidão atual, pois pode deturpar a realidade do que significa esse processo, além de dar força às vozes que procuram minimizar a importância de se combater e punir quem se beneficia de tal relação, Figueira et. al. (2011, 94-95) relata sobre as características da escravidão contemporânea

Ao contrário do escravismo da era moderna, em que o escravo representava uma mercadoria que podia ser objeto de todas as formas características da apropriação mercantil (venda, hipoteca, aluguel, empréstimo) em um mercado de dimensão intercontinental, as formas de escravidão contemporânea ocorrem em circunstâncias que não mais reconhecem como legítimos os direitos de propriedade do senhor sobre a vida do escravo. A escravidão contemporânea acontece nos interstícios da economia de mercado baseada no trabalho livre. As formas de imposição do trabalho escravo contemporâneo emergem fundamentalmente no contexto de transgressões da ordem regular do trabalho livre, como nos impedimentos à livre circulação dos trabalhadores e como violação na aplicação das condições legais dos contratos de trabalho.

Para compreendermos a dinâmica da escravidão contemporânea no Brasil, é necessário situá-la no quadro histórico mais amplo da transição do trabalho escravo ao trabalho livre no Brasil.

Portanto, as diferenças são claras entre as formas de escravidão do período colonial e as que ocorrem no atual momento. Mas da mesma maneira que existem as diferenças, existem as continuidades como: ambiente de trabalho desumano; a coerção física e moral, ameaças e práticas de violência, inclusive assassinatos; e principalmente, a persistência do racismo, em suas várias formas, como mecanismo que justifica a submissão dos trabalhadores a tais condições. Dessa forma, a escravidão, é uma das configurações mais duradouras da dominação produzida no Brasil desde a invasão portuguesa em 1500¹. Figueira $(2004,48)$ relata:

Assim, por força de construção social, manifestada nas pressões de grupos específicos e no seu uso cada vez mais frequente pelo conjunto das organizações oficiais e não oficiais, a modalidade de

1Segundo Gomes (2019) indígenas escravizados foram enviados ao rei dom Manuel I em 1514. Já escravização de africanos em terras brasileiras teria iniciado entre a década de 1530 a 1540, não tendo uma certeza absoluta sobre o ano exato. 
trabalho forçado sobre a qual escrevo tem sido reconhecida como não apenas parecida com a escrava, mas de fato escrava.

Este é o ponto principal da adoção do conceito de trabalho escravo contemporâneo: as relações laborais encontradas são de escravidão e não parecidas ou similares. Martins (2009) também converge nessa discussão quando diz “[...]alguns pesquisadores relutam em dar a essa relação de trabalho o nome que lhe é mais apropriado: escravidão" (Martins 2009, 73). Dessa forma, o Art. 149 do Código Penal brasileiro determina as condições para caracterização desta relação: trabalhos forçados ou jornada exaustiva; condições degradantes de trabalho; restrição de liberdade por dívida ou impossibilidade de locomoção. A violação de qualquer uma das condutas previstas neste artigo já configura trabalho escravo contemporâneo.

A maior parte dos estudos procuram explicar a escravidão contemporânea, buscando uma resposta entorno da necessidade de potencializar a extração de mais-valia a partir da reprodução da escravidão em setores não modernizados ou naqueles que enfrentam elevada concorrência no mercado, como no setor agroexportador e vestuário. Esse fato, daria vantagem econômica aos empregadores que usam dessa prática ( Sakamoto 2011 ). Martins $(2009,82$ ) também fala que esse é um método empregado com o objetivo de ampliar a acumulação de capital: "Essa modalidade de exploração do trabalho se traduz em acumulação primitiva porque é, em parte, produção de capital no interior do processo de reprodução ampliada do capital" (grifo do autor). Dessa forma, para Sakamoto $(2011,391)$ :

O capitalismo redefine formas pré-capitalistas, englobando-as. Nesse sentido, o trabalho escravo contemporâneo não é simplesmente um resquício de práticas anacrônicas que sobrevivem dentro de um contexto moderno, mas uma reinvenção destas, a forma mais degradante de exploração da força de trabalho e negação de direitos que opera nos locais e momentos em que o modo de produção se expande.

De fato, o trabalho escravo contemporâneo é uma forma de espoliação estruturada na dinâmica de acumulação de capital que traz inúmeras vantagens econômicas. Mas do ponto de vista da justificação, o que faz os empregadores submeterem determinados sujeitos a formas tão desumanas de labor? O que leva o empregador a ter uma total indiferença quanto a essa situação? Que relações de poder estão envolvidas em tamanho desprezo? Por que os trabalhadores aceitam laborar nessas condições? São essas perguntas que acreditamos que a teoria da colonialidade ajuda a compreender.

Antes de entrar nesse debate vamos apresentar os dados da escravidão contemporânea no Paraná. Sakamoto $(2020,7)$ constata que:

Ao longo desse período, o trabalho escravo contemporâneo deixou de ser encarado como um problema restrito a regiões de fronteira agropecuária, como Amazônia, Cerrado e Pantanal. Hoje também é combatido nos grandes centros urbanos. Além disso, passou a ser compreendido não como um resquício de formas arcaicas de exploração que resistiram ao avanço da modernidade, mas como instrumento adotado por empreendimentos para garantir lucro fácil e competitividade em uma economia cada vez mais globalizada. 
Os dados obtidos por via dos relatórios de fiscalização dos GEFM's confirmam as afirmações de Sakamoto (2020). Eles mostram que, os setores com mais resgates foram: reflorestamento de pinus e eucalipto, desmatamento e madeireiras $(42 \%)$; cana-deaçúcar $(28 \%)$, erva-mate $(21 \%)$ e trabalhador agropecuário geral $(8 \%)$. Esse último engloba os trabalhadores regatados na cultura do café (19 trabalhadores), no hortifruti (48 trabalhadores), na pecuária (35 trabalhadores). No caso da mineração e carvão vegetal, ocorreram cinco resgates, com 9 trabalhadores: 4 na extração de rochas para calçamento e 5 na produção de carvão vegetal.

A maior parte dos resgates se concentraram na Mesorregião Norte Pioneiro e Noroeste; Metropolitana de Curitiba e nas Mesorregiões Centro-Sul e Sudeste do Estado. Ou seja, pelos números, é possível regionalizar o trabalho escravo contemporâneo em 4 grandes círculos (figura 1).

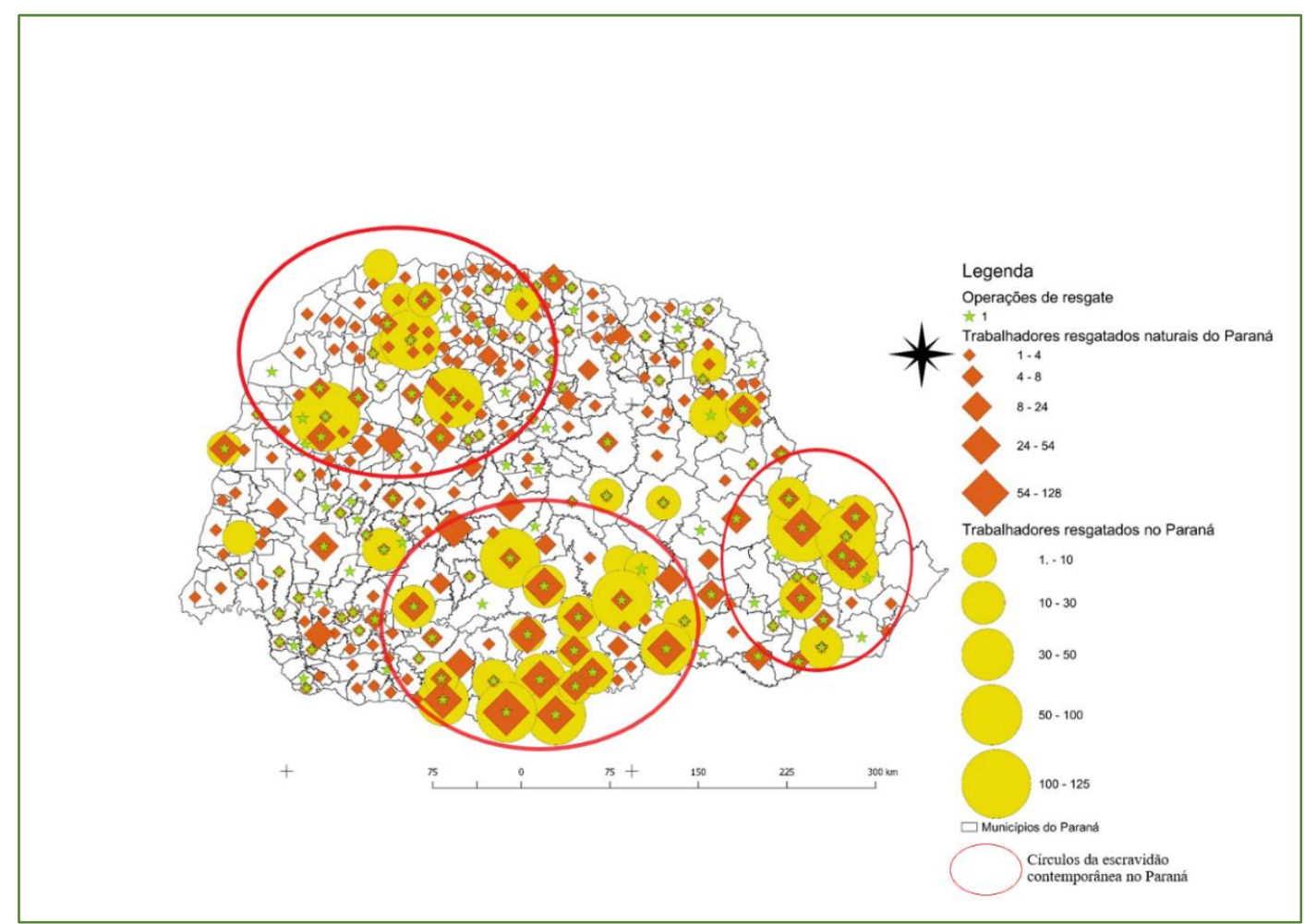

Figura 1. Mapa do número de operações, número de trabalhadores resgatados naturais do Paraná, número de trabalhadores resgatados no Paraná e círculos da escravidão contemporânea no Paraná.

Fonte: Observatório da erradicação do Trabalho Escravo e do tráfico de pessoas (2018), Elaboração: Autor (2019)

O mapa também aponta para uma outra característica importante, a imigração. No símbolo em forma de losango laranja observamos que vários paranaenses foram resgatados longe de suas residências. Rodrigues (2016) e Soares (2017) aponta esse fator como um dos pontos principais levam os trabalhadores a caírem na escravidão moderna. A necessidade de migrara para buscar a sobrevivência, levam trabalhadores urbanos e 
rurais a aceitarem trabalhos extremamente degradantes, Moura (2007, 178) em pesquisas realizadas em Condó-MA aponta:

[...] que eles não se auto-identificam como escravos e aceitam condições consideradas precárias de trabalho, principalmente devido às dificuldades enfrentadas para manter suas atividades agrícolas e, consequentemente, para poder garantir a sobrevivência de seus familiares

Na região do recorte espacial escolhido neste texto (figura 2), os grupos móveis encontraram 502 trabalhadores em situação de escravidão contemporânea, os quais representam 38\% do total do estado. Nesse caso específico, concentram-se no espaço rural, principalmente no trato com erva-mate, soja, no reflorestamento, na pecuária e na produção de carvão vegetal.

A figura 2 permite observar que Palmas, General Carneiro, Clevelândia e Campina do Simão destacam-se no número de trabalhadores resgatados. Eles foram tirados da escravidão contemporânea nas seguintes atividades: reflorestamento 53\%, Erva-Mate $43 \%$, e pecuária, soja e carvão vegetal $3 \%$.

Os dados sobre as características dos resgatados mostram a seguinte situação: baixa escolaridade, com 28\% analfabetos, $62 \%$ não completaram o $5^{\circ}$ ano do ensino fundamental e $8 \%$ não completaram o fundamental II. Sobre a idade, 50\% fazem parte

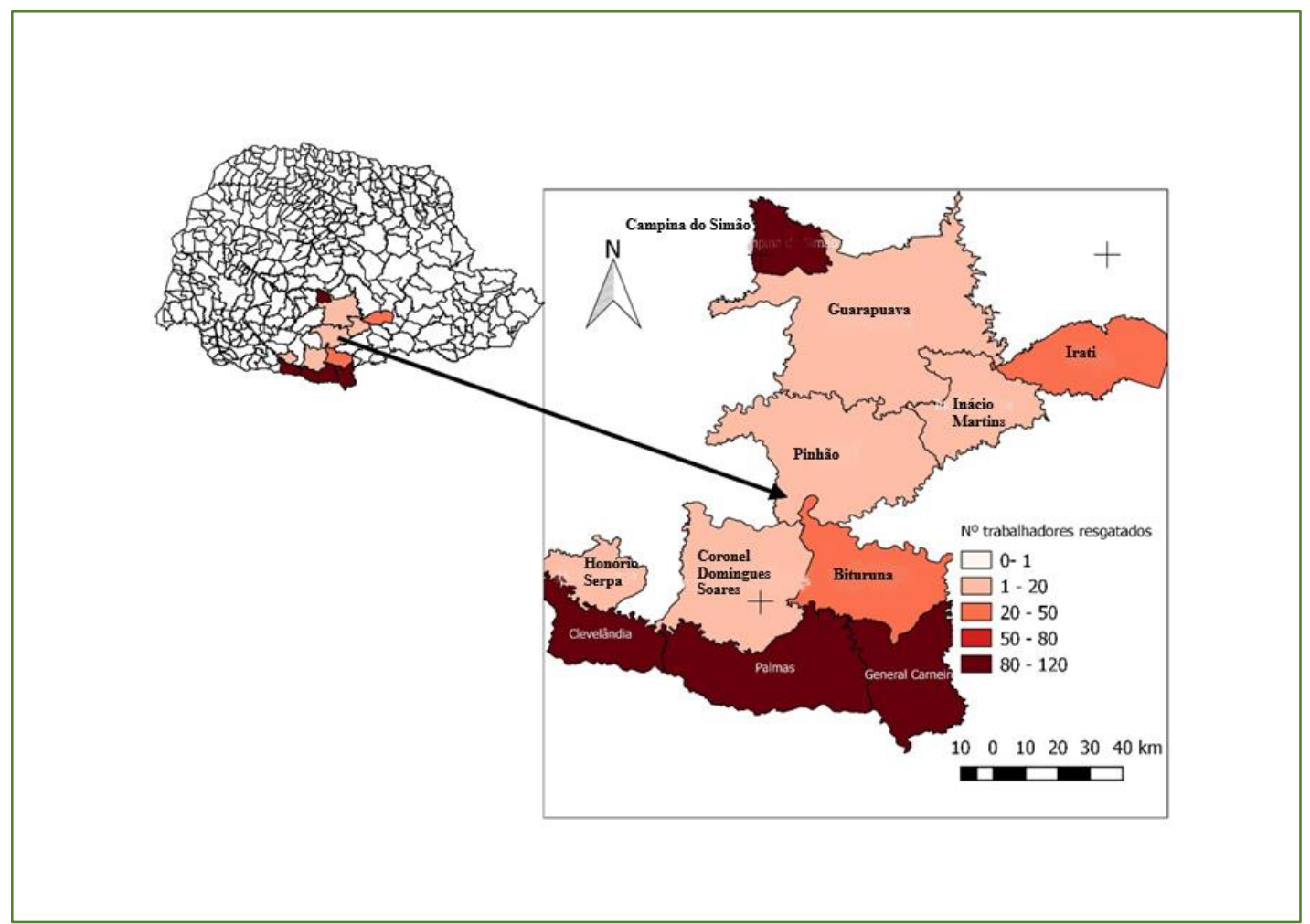

Figura 2 Mapa do trabalho escravo na Região Centro-Sul do Paraná e da quantidade de trabalhadores resgatados por município, de 2005 a 2018.

Fonte:IBGE (2019); Observatório da Erradicação do Trabalho Escravo e Tráfico de Pessoas (2018), elaborado pelo autor (2018). 
do grupo de 30 a 60 anos, compondo a maioria deles, seguido de $43 \%$ de jovens entre 18 a 29 anos e $2 \%$ de pessoas com mais de 60 anos. Também há a presença de trabalho infantil, com $5 \%$.

Esses dados permitem refletir brevemente sobre o papel do não acesso, ou do acesso precário, desses sujeitos à rede pública de ensino em, pelo menos, duas frentes: revelam uma contradição da função do Estado no âmbito educacional e se torna uma via de justificação dos empregadores e empregados resgatados. Ao mesmo tempo em que buscou ampliar a rede de ensino, incluindo um número cada vez maior de crianças e adolescentes nos bancos escolares, não alterou as estruturas da desigualdade social, que continua fazendo os jovens escolherem entre continuar estudando ou trabalhar para ajudar no sustento da família. Ao contrário do que se imagina, uma parte significativa é de pessoas com até 29 anos, ou seja, que, teoricamente, teriam mais chances de estar dentro da sala de aula devido ao recente processo de ampliação do "acesso" ao ensino básico. No entanto, pelos dados coletados pelos auditores, no momento das fiscalizações, esses programas não foram suficientes para mantê-los ou inseri-los nas escolas, muito menos para afastá-los de formas extremadas de superexploração.

O segundo ponto tem relação com o processo de justificação. O leitor verá, mais adiante, que a falta de "ensino" é um instrumento usado pelos empregadores flagrados com trabalho escravo para justificar as terríveis condições oferecidas aos empregados.

Para os trabalhadores, ela também é a causa principal de estarem laborando naquelas condições. O capitalismo introduz na sociedade a necessidade cada vez maior de "formar" mão de obra qualificada e especializada, tratando-a como o único caminho para encontrar um emprego que ofereça condições materiais melhores. Dessa forma, os próprios trabalhadores acabam aceitando que, por não terem estudos, se quiserem sobreviver, a única saída é aceitarem trabalhar em condições extremas de superexploração. Nesse sentido, o nível escolar também se torna um instrumento de dominação. O relato de um trabalhador, resgatado pela segunda vez, coletado pelos auditores, deixa claro essa situação:

QUE com o "P"2 estava trabalhando sem carteira assinada, alojado em barraco de lona plástica; QUE sabia que o trabalho com o " $\mathrm{P}$ " estava errado, mas "fazer o quê?, precisava trabalhar; QUE na região para quem não tem estudo, como o declarante, não tem outro serviço, pois nas firmas precisa de estudo; Que o declarante frequentou apenas um ano de escola [...] (Relatorio de fiscalizaçao, 09.07.2010 Clevelandia) ${ }^{3}$.

Outra característica é que os sujeitos arregimentados para esse tipo de trabalho têm como condição principal a miséria. Nos municípios que compõem o recorte espacial

2 Nome fictício usado para resguarda a identidade dos envueltos.

3 A forma de transcrição é a que consta nos relatórios de fiscalização 
analisado neste texto, $48 \%$ das famílias fazem parte do Cadastro Único ${ }^{4}$ do governo federal, sendo que 16\% delas recebem o Bolsa Família. Evidente que a situação dessas famílias é de extrema pobreza, pois a única renda que recebem vem desse tipo de trabalho. Segundo os próprios relatórios, os trabalhadores não chegam a ganhar mais de 200 reais líquidos por mês. E, mesmo depois do resgate, eles continuaram vulneráveis, fato que contribuí para que um mesmo trabalhador seja resgatado mais de uma vez.

Outro dado disponível sobre a escravidão contemporânea se relaciona à declaração de cor/raça do resgatado. O Observatório da Erradicação do Trabalho Escravo e do Tráfico de Pessoas contabiliza, entre os anos de 2003 a 2018, que, levando em consideração todos os Estados brasileiros, $76 \%$ dos resgatados se declararam pardos, pretos, indígenas e amarelos e $23 \%$ dos resgatados eram brancos. Mas, segundo a mesma fonte de dados, levando em consideração apenas o Paraná, os números se invertem: 45\% dos regatados declararam-se pardos, amarelos, pretos e indígenas; e $65 \%$ brancos. Em razão da presença de pessoas brancas, pesquisadores têm apontado que o trabalho escravo não tem uma raça definida (Rodrigues 2016 e Soares 2017).

Discordamos dessa afirmação, não se pode aceitar que as discussões referentes ao poder do racismo sobre esse tipo extremado de superexploração sejam afastadas ou deixadas em segundo plano. Alves (2019) também aponta na mesma direção, ela diz que esses dados são pouco confiáveis em razão do preenchimento irregular do campo raça nos formulários de seguro-desemprego, fato constado por nós durante a leitura dos relatórios. Mas mesmo que os dados não tivessem problemas, as discussões sobre o papel do racismo nesse tipo de relação laboral não podem ser afastadas, isso desde várias perspectivas de análise, das quais, destacam-se aqui duas: a primeira, relacionada à identidade negra nos países que sofreram processo de colonização e, a segunda, relacionada à definição de racismo em suas várias faces.

Sobre a primeira perspectiva: é clara a intensidade da estigmatização da questão da identidade negra no Brasil, principalmente nos estados da Região Sul. Um dos resultados mais perversos e sólidos da colonialidade foi a criação da auto negação das identidades negras e indígenas. O ser negro e indígena sofreu um contínuo processo de degradação social pela civilização moderna/colonial, que gerou um processo de negação interna. Bernadino (2002) mostra como o mito da democracia racial ${ }^{5}$, juntamente como

\footnotetext{
4 O Cadastro Único é um programa federal que reúne os dados das famílias em situação de pobreza ou extrema pobreza no Brasil e que podem acessar programas sociais, como o Bolsa Família. Estão incluídas no programa famílias que têm renda per capita menor que $\mathrm{R} \$ 522,00$ reais ou até 3 salários mínimos. 5 A democracia racial foi uma ideia implantada por Gilberto Freyre, na década de 1930. Ela pregava que, em razão do Brasil ser um país com elevado grau de miscigenação e diversidade racial, não existiria racismo e que todas as raças teriam as mesmas oportunidades. Ideologia que se mostrou um mito em razão dos fatos que mostram como o racismo mantém a discriminação em todas as esferas da vida.
} 
o mito do senhor benevolente ${ }^{6}$ e a política de branqueamento ${ }^{7}$ tiveram o papel de suprimir e desvalorizar o negro e o indígena em todos os seus aspectos, enquanto se valorizava a ideia racista de "superioridade branca". Nesse sentido, o ideário de branqueamento tinha como objetivo a gradual eliminação do negro e do indígena, por meio imigração europeia e da mestiçagem.

O mestiço vive em uma fronteira criada entre esses dois grupos "Teoricamente, eles têm três opções: optar pela identidade de um dos grupos; construir a sua identidade mestiça; ficar perdidos sem nenhuma opção" (MUNAGA, 2019, 110). Isso faz o sujeito ter dificuldade em se reconhecer. Evidentemente, essa indecisão e a transformação das discussões sobre raça e cor de pele são fortemente influenciadas pelo poder alienante da ideologia do branqueamento. Logo, muitos brasileiros negros e indígenas não se identificam como pertencentes a esses grupos e acabam buscando uma aceitação a partir do mundo branco.

Fanon (2008) mostrou com contundência o poder da alienação do ideário branco eurocêntrico, implantado pelo colonialismo, sobre os sujeitos negros, indígenas e mestiços, marginalizados pela colonialidade. Assim, o questionamento é: sabendo da complexidade da auto identificação a partir da cor de pele, principalmente para os mestiços, dos ataques constantes à identidade negra e indígena no Brasil, da promoção histórica de um ideário branqueamento da população, será que, de fato, os números apresentados refletem a realidade? Será que podemos afastar o poder do racismo, diante desses números, nas reflexões sobre a escravidão contemporânea? Nesse sentido, é necessário, no mínimo, ampliar a reflexão em relação aos números e, especialmente, evitar diminuir o poder do preconceito de raça no entendimento da escravidão contemporânea, erro comum quando se analisa esse problema apenas sob a perspectiva da luta de classes. Em um país onde os números da desigualdade social, da violência e da pobreza estão diretamente ligados à questão de raça, não nos parece que a escravidão contemporânea seja isenta dessa relação de poder.

A segunda perspectiva: ao afastarem as discussões sobre o papel da questão racial nas análises da escravidão contemporânea, pesquisadores e estudiosos têm, praticamente, suprimido o papel do racismo nesse contexto, pois o reduzem apenas para o âmbito fenótipo, que tem uma importância de primeira ordem, mas, na realidade, ele

6 O mito do senhor benevolente tem relação com a tentativa da historiografia oficial de construir uma ideia falsa de que a escravidão no Brasil foi "menos agressiva" em razão dos senhores escravocratas brasileiros serem benevolentes e menos violentos com seus escravos. Fato falso e desmentido pela realidade, que revelou o grau elevadíssimo de violência e desprezo pela humanidade que marcaram a história da escravidão com sangue, lágrimas e suor negro e indígena.

7 A política de branqueamento está relacionada à chegada de imigrantes europeus para substituírem a mão de obra escrava pós abolição, em 1888, e para desenvolverem agricultura, principalmente no Sul do país. Com essas ações, a elite crioula racista brasileira esperava branquear a população, tanto pela chegada de um contingente considerável de brancos, quanto pela miscigenação, a qual, teoricamente, levaria, com o tempo, a um processo de branqueamento. Esse ideário racista pensava que apenas brancos europeus teriam a capacidade de "desenvolver" o país, pois os negros e indígenas não eram capazes de tal missão em razão da sua suposta inferioridade racial. 
é acionado a partir de vários aspectos, que vão desde fenótipos, econômicos, culturais, religiosos, epistêmico e níveis de conhecimento. O racismo está diretamente relacionado ao processo de desumanização do ser humano a partir de algum aspecto. Esse processo teve origem na colonização (Quijano 2005).

Durante esse período, passou-se a questionar a humanidade dos sujeitos pertencentes às várias nações originárias dos continentes americanos e africano, a partir da ideia de raça. As discussões giravam em torno, por exemplo, se essas pessoas, de fato, pertenciam ao reino dos "homens", se possuíam "alma" e se tinham capacidade de raciocinar.

A partir desse momento, determinados seres humanos passaram a ser posicionados abaixo da linha da humanidade, permitindo que inúmeras atrocidades fossem cometidas. Se a religião cristã e a política abriram as portas para esses tipos de questionamentos, atualmente, uma parte da ciência e a política tomam protagonismo no contínuo processo de classificação social a partir da desumanização (Mignolo 2017).

Dessa forma, o que nós temos é uma mescla de vários tipos de racismos que se relaciona com outras formas de dominação, como de classe e gênero. Esse racismo, ou, nas palavras de Grosfoguel (2011), racismo epistêmico, tem o papel fundamental na compreensão da escravidão contemporânea. O principal consenso entre as equipes de fiscalização, judiciário e pesquisadores é o grau elevadíssimo de degradação onde houve o flagrante de trabalho escravo. São locais e práticas que mostram materialmente como continua vivo o processo desumanização do ser. Assim, para Grosfoguel (2011), o racismo passa a existir quando determinados seres humanos são inferiorizados e classificados abaixo da linha do humano em razão de uma suposta "animalidade", inteligência inferior ou pela falta de racionalidade.

Nos relatórios, foi identificada a presença, entre os resgatados, de sujeitos pertencentes a comunidades tradicionais do Paraná e camponeses assentados.

Esses sofrem de forma ainda mais forte o racismo epistêmico, pois são inferiorizados para além da sua cor de pele, seu modo de vida, suas tradições, seus saberes e cultura são rebaixados e, consequentemente, tem sua humanidade questionada, são tratados ignorantes, atrasados e um empecilho ao desenvolvimento, se tornando alvo da violência capitalista e tendo seus territórios espoliados e sua força de trabalho superexplorados, como no contexto analisado neste texto. Por exemplo, em um resgate feito em Clevelândia, em 2010, alguns trabalhadores declararam residir no bairro São Sebastião do Rocio, local onde se encontra a comunidade quilombola Aldelaide Maria da Trindade Batista, e no Bairro Lagoão, onde está localizada outra comunidade quilombola: a Tobias Ferreira (Relatòrios de Fiscalizaçao GEFM, 2010). Nesse mesmo caso, alguns sujeitos declararam que residiam no Assentamento Paraíso do Sul, em Palmas/PR, e outro se declarou indígena, morador da periferia de Clevelândia. Em outra operação, no ano de 2009, no mesmo município, os auditores fiscais encontraram entre os trabalhadores submetidos a esse tipo de extrema exploração, indígenas da Terra Indígena Alto Pinhal, que ainda está em processo de demarcação, localizada em Clevelândia. Da 
mesma forma, em 2007, camponeses faxinalenses ${ }^{8}$ das comunidades Faxinal dos Santos, em General Carneiro/PR, e Faxinal Marmeleiro de Cima, em Rebouças/PR, foram resgatados. Neste texto, não temos espaço e condições de analisar detalhadamente a situação dessas comunidades, entretanto, são comunidades tradicionais que vêm sofrendo, historicamente, inúmeras violações e ataques por parte da elite crioula ${ }^{9}$ da região em razão da sua forma de viver e produzir no espaço ${ }^{10}$.

Nesse sentido, o racismo cumpre o papel de separar aqueles que têm direito a uma vida "plena" e aqueles que são fadados à marginalização, superexploração e a coerção sobre seus corpos e territórios. A produção do espaço geográfico do círculo do trabalho escravo contemporâneo na região Centro-Sul do Paraná, influenciada pela civilização moderna/colonial capitalista, não possibilitou que o povo pobre, negro, indígena, mestiço e camponês tivesse possibilidades de se reproduzir de forma digna, com os mesmos direitos conquistados pelos trabalhadores brancos da elite e da classe média, que vivem dentro da relação capital-trabalho regulado pelo Estado, e do acesso à terra ${ }^{11}$. Portanto, o espaço geográfico é marcado por uma fronteira atravessada por uma linha abissal (Santos 2007), cada vez maior, que divide quem vive na zona do ser e do não ser (Fanon 1979). Os trabalhadores resgatados experienciam essa fronteira de forma ampla, que vai do trabalho à vida social, à cultura e à economia. A linha abissal que sustenta essa fronteira foi criada, e é mantida, pela colonialidade em suas várias faces, a qual tem o racismo, em suas múltiplas dimensões, como mecanismo de poder privilegiado.

Essa linha, para Santos (2007), é a divisão, a partir de vários níveis escalares, entre o lugar habitado por seres "civilizados", partícipes da modernidade eurocêntrica, consequentemente, humanos "desenvolvidos", e entre o habitado, segundo a visão eurocêntrica, pelos "incivilizados", "atrasados", "subdesenvolvidos", "ignorantes", etc., ou seja, pelos "sub-humanos". Esse mundo dividido, mas interconectado é, para Fanon (1979), o que caracteriza a zona do ser e não ser, que não se trata apena de localidades geográficas divididas em um mesmo espaço, mas das posições ocupadas por determinados sujeitos na distribuição do poder e na determinação do que pode ou não

8 Faxinais são comunidades rurais camponesas que têm, entre outras características, a criação comunitária de animais em área de floretas nativas em terras coletivas, a produção para o auto consumo e extrativismo vegetal, principalmente, a coleta de erva-mate e pinhão.

9 Usamos o conceito de elite crioula acompanhando os pensamentos de Casanova (2006). Ele considera que após a abolição uma elite interna crioula, com laços ideológicos e sanguíneos com os colonizadores europeus, foram responsáveis por propagar uma história de dominação e violência contra os povos indígenas no México. Fato que encontramos similaridades com o processo histórico brasileiro.

10 Essas comunidades têm passado por inúmeras violações, desde aquelas que não têm seu território garantido, como a Comunidade Indígena Alto Pinhal, e outras que sofrem para ter seu modo de vida respeitado, acesso a mercado para sua produção, bem como políticas públicas que possam ajudar a manter suas tradições e costumes.

11 Aqui não estamos avaliando se a educação ou a inserção no circuito econômico da modernidade capitalista é o melhor caminho e opção para as classes subalternizadas, mas, tão somente, apresentamos essas informações como mais um conjunto de fatores que confirmam a forma excludente e racista da formação social construídas por essa civilização. 
existir. A primeira, a zona do ser, é do privilégio racial branco, na qual a economiamundo capitalista busca introduzir mecanismos de exploração menos violentos na extração de mais-valia, como é o caso do trabalho regulado pela legislação trabalhista atual, no qual o conjunto de direitos, como o salário mínimo, são respeitados e as normas de segurança do trabalho seguida Ela reparte, dentro da elite hegemônica minúscula, os resultados da acumulação capitalista e, dessa forma, goza do acesso a espaços e equipamentos de primeira linha, tem garantidos direitos amplos por meio do Estado, que atua como um garantidor da felicidade e da paz, mesmo que, para isso, tenha que usar da força despótica contra aqueles incluídos marginalmente no mundo moderno/colonial.

Já a segunda, a zona do não ser, é habitada pelos seres humanos subalternizados pelo mundo eurocêntrico, desde o período colonial (quando pensamos a América Latina). A esses é negado e retalhado o direito à vida, a suas tradições, a suas ancestralidades, a suas crenças religiosas, portanto, à sua cultura. Também ao trabalho digno, ao sistema jurídico, à moradia, à água tratada e saneamento, à alimentação, à escolarização, equipamentos urbanos, o acesso a políticas públicas, etc., ou seja, uma infinidade de violações e negações, que são constantemente perpetrados pelo Estado, pela mídia e, principalmente, pela elite global, ou seja, pelo mundo moderno/colonial. Como relata Fanon (1979), ela é crivada pelo racismo, tanto estatal, que abandona as regiões habitadas por esses sujeitos à própria sorte, como pela própria civilização moderna/colonial, que deteriora o ser humano e o trabalho exercido por ele com os piores adjetivos disponíveis.

Nesse sentido, desde o princípio, tanto o sujeito, quanto as atividades desenvolvidas por ele, eram e continuam sendo rebaixadas dentro de uma hierarquia que permanece desvalorizando o trabalho manual, doméstico e rural. Por essa razão, o trabalhador resgatado vive a colonialidade do ser, poder, saber e do trabalho ${ }^{12}$. Assim, no próximo subcapítulo, analisaremos a colonialidade no trabalho escravo na região aqui estudada.

\section{A colonialidade do trabalho, do poder e do ser no círculo da escravidão contemporânea na Região Centro-Sul do Paraná}

O trabalho é objeto de hierarquização social e exploração desde antes do início do mundo moderno/colonial, em 1492 (Wallerstein e Quijano 1992). No entanto, é a partir desse momento que a categoria raça torna-se um elemento primordial na classificação social e na definição daqueles que têm direito à propriedade, ao trabalho regulado e livre, à participação política, à cultura, etc.. Devido à cosmovisão racista ocidental colonizadora, os sujeitos viventes na zona do não ser foram transformados em objetos de

12 O espaço deste artigo não possibilita uma discussão aprofundada sobre como cada uma dessas dimensões da colonialidade age sobre os sujeitos resgatados. No entanto, acreditamos que os elementos apresentados neste texto permitem abrir um horizonte mais amplo na busca da compreensão desse grave problema social. 
exploração para maximização da acumulação capitalista, por meio da reprodução da sua forma primitiva, chamada por Harvey (2004) de espoliação.

A história mostra que o trabalho, principalmente o manual, possuía valores sociais e morais muito diferentes, dependendo da civilização e do tempo. Nem sempre o trabalho era tratado como meio dignificador da existência e tratado como fundamental para vida dos seres humanos. Para a europeia, civilização que foi a responsável por impor um modo de vida específico em quase todos os cantos do planeta a partir da colonização do Sul global, sendo a que nos interessa neste estudo, durante muito tempo, foi tratado como algo depreciativo, destinado às classes mais subalternizadas da estrutura social, como revelam os estudos de Marañón-Pimentel $(2017)^{13}$. Essa noção surge no período da Grécia Antiga. Aristóteles classificava o labor manual como impróprio para os humanos de nível superior, no caso a "elite aristocrática". Para ele, deveria haver definição clara da divisão social do trabalho. O labor manual, destinado à sobrevivência, necessitava ser executado pelas classes subalternas e escravos, que não teriam tempo e capacidade de pensar.

Portanto, os atos de mando e pensamento são papéis exclusivos da elite, a qual deveria ficar afastada das tarefas manuais e de grande desgaste físico para que pudesse ter tempo livre para tomar as melhores decisões de comando, dedicar-se à política, à cultura, à arte, à religião e à "ciência”. Para Marañón-Pimentel (2017), esse foi o momento em que "los filósofos más notables, entre ellos Platón, sócrates y aristóteles, quienes legitimaron una visión negativa del trabajo, limitándolo a lo físico y mecánico hecho por esclavos, labradores, comerciantes y artesanos [...]" (Marañon-Pimentel 2017, 63).

Este pensamento influenciou a construção de uma forma racista e sexista de divisão social do trabalho na civilização moderna/colonial capitalista, dessa forma, esse processo é fundamental para entender os conflitos e as explorações enraizadas desde a colonização em toda América Latina, a qual persiste e é ressignificada nos tempos atuais, como defende a teoria da colonialidade (Quijano 2014).

A formação dessa civilização criou uma noção de tempo linear e única. As populações passaram a ser classificadas como atrasadas, sem história e primitivas desde uma perspectiva que considerava legitima apenas o grau de "humanidade" atingido no mundo europeu. Para tanto, como defende Dussel $(1993,8)$ o ego conquiro antecipou o ego cogito da modernidade "Mas 'nasceu' quando a Europa pôde se confrontar com o seu "Outro" e controlá-lo, vencê-lo, violentá-lo: quando pôde se definir como um "ego" descobridor, conquistador".

A colonização da vida cotidiana do índio, do escravo africano pouco depois, foi o primeiro processo "europeu" de "modernização", de civilizaçãode "subsumir" (ou alienar) o Outro como "si esmo"; mas agora não mais como objeto de uma práxis guerreira, de violência pura - como no caso de Cortês contra os exércitos astecas,[...], e sim de uma práxis erótica, pedagógica, cultural, política, econômica, quer dizer, do

13 Marañón-Pimentel (2017) faz um resgate histórico e uma crítica a construção do conceito de trabalho muito pertinente e profunda. Convido os leitores a leitura de sua obra sobre o título: Una crítica descolonial del trabajo. 
domínio dos corpos pelo machismo sexual, da cultura, de tipos de trabalhos, de instituições criadas por uma nova burocracia política, etc., dominação do Outro. É o começo da domesticação, estruturação, colonização do "modo" como aquelas pessoas viviam e reproduziam sua vida humana. Sobre o efeito daquela "colonização" do mundo da vida se construirá a América Latina posterior: uma raça mestiça, uma cultura sincrética, híbrida, um Estado colonial, uma economia capitalista (primeiro mercantilista e depois industrial) dependente e periférica desde seu início, desde a origem da Modernidade (sua "outra-face": te-íxtli) (Dussel 1993, 50)

Ou seja, antes da perspectiva eurocêntrica se tornar a única alternativa possível de civilização, ela teve, obrigatoriamente, que conquistar e massacrar física e simbolicamente o "Outro". Portanto, pagãos e não cristãos submetidos à escravidão tinham no trabalho forçado um meio para conversão ao mundo moderno/colonial cristão. Dessa forma, "[...] a colonização é representada como um veículo de civilização, e a escravidão é interpretada como um meio para ajudar o primitivo e sub-humano a se tornar 'disciplinado" (Maldonado-Torres 2017, 588).

A elite colonial justificou a escravidão com base na separação ontológica entre seres humanos e aqueles não tão humanos assim e, por essa razão, poderiam se tornar escravos. Essa posição foi resguardada na história pós independência, abolição e Proclamação da República no Brasil por uma elite crioula que buscava reproduzir os hábitos eurocentrados aqui instalados. Dessa forma, a partir desse período, o trabalho manual se torna instrumento de desumanização, principalmente os realizados no espaço rural e doméstico. Tratar o trabalhador rural e as domésticas com indiferença, com níveis alarmantes de negação da humanidade é uma tradição que se conservou na história brasileira e tem um lastro histórico ligado diretamente ao racismo e a escravidão ( Souza 2017).

Dessa forma, os resultados das operações de combate ao trabalho escravo têm mostrado que a elite dominante fez predominar, de forma nada contraditória, a divisão teorizada por Aristóteles para o sujeito subalternizado pela colonialidade e o das divisões de classe para os trabalhadores de origem Eurocêntrica, fato que deixa claro a heterogeneidade histórico estrutural da civilização moderna/colonial capitalista na América Latina. Tanto uma forma quanto outra é baseada no trabalho abstrato, mas com qualidades singulares e níveis de violência bem diferentes entre elas. Grosfoguel (2012, 95) contribui nesse debate: "En la dialéctica del «Yo» y el «Otro» dentro de la zona del ser hay conflictos, pero no son raciales porque la humanidad del otro oprimido es reconocida por el «Yo» opresor [...]" (Grofogel, 2012, 95).

O relato do autor é primordial para o entendimento do significado da escravidão contemporânea. Os conflitos dentro da zona do ser, gerados pelo capital, são perversos e escancaram as injustiças sociais do sistema. No entanto, como alerta o Grosfoguel (2012), os que ocorrem dentro da zona do não ser são qualitativamente piores e mais violentos, inclusive na esfera do trabalho, porque eles partem da negação da humanidade da vítima. Assim, tanto a vítima quanto o trabalho que, historicamente, foi-lhes destinado (manuais) são objetos da colonialidade. Nesse sentido, podemos falar de uma colonialidade do trabalho. O trabalho rural, o doméstico e da construção civil foram, no 
período escravocrata, destinados aos escravos e a uma parcela da população considerada livre, mas que vivia em completa servidão ${ }^{14}$. Por essa razão, guarda-se, até os dias atuais, um desvalor ao trabalho rural e doméstico e os números da escravidão contemporânea não deixam dúvidas sobre esse fato.

Dessa forma, concorda-se com Bernadino-Costa (2012,453), quando diz:

A colonialidade do trabalho é o dínamo dessa estrutura social e dessa formação cultural, criadoras de nichos de exploração no centro do capitalismo globalizado, formando uma lógica de desvalorização do trabalho feminizado e racializado, bem como formando uma lógica desumanizadora dos sujeitos que desempenham esse trabalho.

Assim, tipos específicos de trabalho também são instrumentos de desumanização social. É importante destacar essa questão para compreender a escravidão contemporânea e por que ela ocorre em determinados setores, com determinados sujeitos. Em uma fiscalização, ocorrida em 2009, na região do recorte espacial analisado neste texto, a equipe do GEFM chegou à seguinte conclusão:

Nota-se também, por parte dos donos das áreas, onde a erva-mate é extraída uma indiferença completa. Trata-se de empresas estruturadas e com pessoal próprio nas áreas de Recursos Humanos, Segurança e Saúde do Trabalho, que atendem grande parte das exigências em matéria da legislação do trabalho em outros setores da empresa, inclusive nas áreas florestais, porém ao que parece, não sentem que as normas que aplicam diariamente aos demais trabalhadores, deve ser aplicada aos cortadores de erva-mate. É como se esta atividade inexistisse para estes profissionais. (Relatório de fiscalizaçao GEFM, 2009, 13).

Os fatos que os grupos móveis nos revelam mostram que determinados tipos de trabalho, em especial, o rural e o doméstico, são atividades que a elite crioula tem dificuldade de reconhecer não só o valor material, mas também o simbólico. Como mostramos anteriormente, $100 \%$ dos resgates na região do círculo do trabalho escravo contemporâneo na região Centro-Sul do Paraná foram em atividades rurais, nos setores de reflorestamento, da erva-mate, da soja e da pecuária. No Paraná, segundo o Radar SIT, $71 \%$ dos resgates ocorreram em atividades rurais; no Brasil, a porcentagem sobe para 78\%. Das atividades urbanas, têm maior destaque a construção civil e a doméstica (Observatório Do Trabalho Escravo E Tráfico De Pessoas E Radar Sit 2018). Dessa maneira, analisando os relatórios de fiscalização, verificamos que $90 \%$ dos trabalhadores resgatados não possuíam carteira de trabalho assinada e recebiam pela produção, ou seja, estavam excluídos da formalização do vínculo empregatício, além de laborarem em condições que negam a humanidade.

Pedro, entrevistado durante os trabalhos de campo, não deixa dúvidas quanto à situação deplorável a qual era sujeitado:

14 Na região em estudo, eles ficaram conhecidos como "agregados". Em sua maioria, eram camponeses caboclos sem terras. Laboravam para os grandes latifundiários da época e recebiam como pagamento o local de residência e alimentação para a família. Alguns registros históricos mostram que eles laboravam em conjunto com escravos em algumas atividades, como nos moinhos de beneficiamento da erva-mate (Abreu 1981). 
[...] Como era viver no barraco de lona assim? Pedro ${ }^{15}$ - A era uma situação precária no extremo, sem higiene nenhuma cara... a situação era muito difícil.... ainda hoje têm pessoas, agora o Ministério do trabalho tá pegando firme e tá acabando com isso. Autor-Quais as dificuldades maiores de ficar na lona? Pedro- Ah frio né, chuva... era tudo improvisado... Autor- era muito frio? Pedro- Frio, inverno aí... conforme a região era mais frio! (Pedro 2018).

Além desse ambiente degradante, os trabalhadores contraíam dívidas com o empregador para a compra de ferramentas de trabalho, construção de alojamento de lona e alimentação. Só ganhavam nos dias efetivamente trabalhados, mesmo estando nas frentes de trabalho, disponíveis ao empregador. Os trabalhadores, em sua maioria, ficavam alojados em barracos de lona preta, improvisados na sede das fazendas, onde extraiam erva-mate ou pinus e eucalipto, como a fala de Pedro reforça. Eles também não possuíam lugar próprio para as necessidades higiênicas e fisiológicas, não era fornecida água potável, bem como lugar para guardarem alimentos. Quando chovia ou em dias de muito frio ${ }^{16}$, tudo que estava dentro do barraco ficava molhado.

Eram obrigados a tomarem banho em rios, mesmo com temperaturas que chegavam abaixo de $0^{\circ} \mathrm{C}$. Dormiam no chão ou em tarimpas ${ }^{17}$, enfim, uma situação lastimável, que tem a indiferença com o outro como marca principal desse tipo de relação. O depoimento de um resgatado, coletado pela equipe de fiscalização, em 2009, no município de Clevelândia, ajuda a entender a situação dos trabalhadores:

QUE trabalha para a ervateira há aproximadamente 7 anos; [...] QUE foram trazidos de caminhão [para a frente de trabalho]; QUE todos foram trazidos na carroceria do caminhão;[..] QUE o valor da arroba é acertada com o capataz do Sr. P.; QUE o alojamento, cobertas, comida, tudo foi providenciado pelos trabalhadores; QUE trabalham de domingo a domingo das 6:00 às 18:00 horas; QUE nem sempre dá para almoçar e ficam sem comida nem água no trabalho do corte; QUE arrumam água $\mathrm{p}$ / beber dos olhos d'água na área do corte; QUE fazem suas necessidades no mato e utilizam o mato para se limpar; QUE faz muito frio à noite aqui no alojamento; QUE toma banho no rio, QUE o local do corte é meia hora de caminhada daqui do alojamento; [...] QUE recebem R\$ 1,40 por arroba e o pagamento é feito a cada vinte dias; QUE os trabalhadores usam bota, facão e uma escada para cortar a erva, QUE tudo foi comprado pelos trabalhadores[.... Q QUE cortam erva nos dias de chuva também para garantir a produção [...]". (Relatório De Fiscalização GEFM 2009).

O depoimento mostra a total indiferença do empregador frente à situação em que estava laborando, inclusive durante muito tempo ( 7 anos no caso deste trabalhador). Além desse ambiente extremamente degradante, contraíam dívidas com itens que seriam de responsabilidade do empregador, chegando a não receberem nada ao final do mês, como relata este outro trabalhador "QUE as vezes o dinheiro que recebem dá para

15 Pedro é um nome fictício.

16 A região em análise é a mais fria do Paraná. Em dias de temperaturas muito baixas, durante a noite, a lona plástica gera um processo de liquefação no interior do ambiente, deixando roupas de cama e outros objetos úmidos, fato que piora as condições térmicas dos barracos usados como alojamento.

17 É uma forma improvisada de cama feita com o uso de galhos de árvores cortados pelos trabalhadores, no momento da construção dos alojamentos. 
pagar apenas a comida, outras vezes sobra um pouquinho, que é ruim viver assim." (Relatório GEFM 2009). A escravidão por dívida ou a peonagem, como afirma Martins (2009), compõe os processos de reprodução da acumulação primitiva e, por tanto, se soma a reprodução ampliada do capital, alargando o trabalho não pago e se apropriado do mínimo necessário a subsistência do trabalhador. A figura 2 traz algumas imagens das condições degradantes a que os trabalhadores eram obrigados a se submeterem, em Clevelândia-PR e Inácio Martins-PR. As imagens permitem ter alguns exemplos de parte da realidade laboral desses sujeitos.

A figura 3 mostra os barracos usados como alojamento, a forma como era armazenada a alimentação, os locais de coleta de água e de higiene. As imagens e os depoimentos não deixam dúvidas do desrespeito a todos os direitos humanos básicos. A elite flagrada com trabalho escravo usa de argumentos racistas para manter esses povos dominados e explorados. O depoimento de um empregador é esclarecedor nesse sentido:

Porque, se for verificar as condições desse povo na cidade, estas não são diferentes daquelas constatadas no mato. Essa nossa região é uma região de um povo muito pobre, e não tem uma condição de vida boa aqui na cidade. A mesma condição que ele tem aqui na cidade ele têm lá no mato. Para se ter uma ideia, se você chegar no barraco deles, você vai dar de cara com a falta de higiene. Mesmo que você faça uma patente lá no mato, eles não vão usar... Eles vão no mato, está na cultura deles, sendo alguns são índios. [...]. Este povo é bravo. Para nós os mandar tomar banho, se limpar, é muito difícil, e eles são bravos (Lima; Surkamp, 2012, 69) (grifos nosso).

O empregador que deu esse depoimento é dono de uma das ervateiras que aliciavam mão de obra para laborar nas fazendas da região. As justificativas usadas por ele transparecem a colonialidade do poder, ou seja, a prática de explorar e dominar a partir de características raciais que foram construídas e cimentadas pelo colonialismo.

Observem que a comparação do "empresário" da situação de pobreza e de "costume" de vida no "mato" está diretamente ligada aos indígenas. Outro ponto, na fala, que destacamos é o adjetivo "bravo", usado para determinar a característica de animais. Esse termo foi comumente empregado para definir o grau de resistência dos indígenas frente à colonização. Como exemplo, temos o depoimento, de 1880, do juiz municipal de Palmas/PR, Arlindo Silveira Miró, destinado ao presidente da província do Paraná, João José Pedrosa: "Informa que os índios "bravos" assaltaram a roça de Antônio Ferreira de Freitas,[...] o delegado de polícia seguiu para o local do crime, com uma escolta acompanhada por índios "mansos", a fim de reduzir aqueles indígenas" (Arquivo Público do Paraná 2009, 358). Assim, a dualidade bravo/manso e outras como selvagem/civilizado, primitivo/moderno, atrasado/desenvolvido, etc., são narrativas construídas pela sociedade moderna/colonial para dividir os sujeitos que podem ter seus territórios expropriados e sua força de trabalho superexplorada.

A prática de aproximar parte da população a aspectos da "natureza" e reduzir a sua cultura a possíveis hábitos higiênicos da sociedade moderna eurocêntrica, como se o ambiente oferecido, de fato, permitisse, é revelador da hierarquização a partir de aspectos racistas. Souza $(2017,16)$ descreve essa relação como culturalismo racista, que é usado pela elite para esconder o "paradigma" do racismo científico: "[...] O falso rompimento com o racismo científico é de fácil comprovação. Quando se apela para o 'estoque 
cultural' para explicar o comportamento diferencial de indivíduos[...]". Castro-Gomez (2005) relata que a urbanidade eurocêntrica é um dos principais mecanismos para disciplinar e separar determinados sujeitos que não se comportavam de acordo com o estilo "moderno" de vida, em um processo de colonização da vida cotidiana, como aponta Dussel (1993). Ou seja, para ser considerado verdadeiramente humano, é necessário seguir as regras de "etiqueta" e de "estética" da cultura colonizadora. Por essa razão, a escravidão contemporânea vai ao encontro do que Maldonado-Torres (2018) argumenta, quando usa do conceito de catástrofe metafísica e diferença subontológica para analisar como a modernidade naturalizou a exploração, a expropriação e o extermínio das populações subalternizadas:

Um ponto de partida para essa modernidade foi, portanto, o postulado de uma separação que quebrou com, ou pelo menos começou a tornar irrelevante, a noção de uma cadeia que conectava todos os seres ao divino. Isso é o que eu nomeio de catástrofe metafísica, uma catástrofe que é ao mesmo tempo ontológica, epistemológica e ética. A catástrofe metafísica inclui o colapso massivo e radical da estrutura Eu-Outro de subjetividade e sociabilidade e o começo da relação SenhorEscravo. Isso introduz o que eu denominei em outro lugar de diferença subontológica ou diferença entre seres e aqueles abaixo dos seres. (Maldonado-Torres 2018, 675)

A diferença subontológica, originada pela catástrofe metafísica, é a justificação para que toda opressão sobre os povos considerados de um nível mais baixo siga sendo reproduzida. Diante disso, a escravidão e outras formas de exploração tornaram-se eixo estruturante do sistema mundo moderno/colonial capitalista. Desde Aristóteles, quando esse buscou teorizar a "escravidão natural", que o mundo eurocêntrico vem construindo argumentos para justificar as violências contra o "Outro".

Outra informação verificada na escravidão contemporânea, no círculo que está sendo analisado, é a presença de gatos transvestidos na figura de empreiteiros. Em muitos dos casos verificados, o gato labora nas mesmas condições que os trabalhadores contratados por eles, ganhando apenas uma compensação financeira maior. O fato de empreiteiros contratarem, por meio de terceirização, outros trabalhadores e submetê-los ao trabalho escravo contemporâneo não é contraditório. Pelo contrário, é um sinal ainda mais forte da presença da colonialidade, que sempre buscou roubar a subjetividade de determinados sujeitos para expandir o seu poder de dominação. Essa é uma das faces da colonialidade do ser (Maldonado-Torres 2007), ou seja, sujeitos subalternizados que se identificam e se aliam à dominação exercida pela elite, buscando um benefício individual.

A outra face são daqueles que, devido à normalização de situações que ultrapassam os limites da humanidade na sua vida cotidiana, não conseguem entender ou fugir do nível violento de exploração exercido sobre eles, ou seja, o ambiente imposto de miséria, de privações, de violência, que acaba por "normalizar" as violações no ambiente de trabalho, além da necessidade de encontrar o sustento familiar, tornandose escravos da "precisão"18 (Moura 2008).

18 Para a autora "escravos da precisão" são trabalhadores rurais que necessitam buscar renda para sobreviverem na venda da sua força de trabalho, em razão de processos de expulsão de suas terras ou da 
Portanto, a colonialidade do poder e do ser ajuda a revelar que a dominação surgida com o colonialismo se perpetua nas relações espaciais, dentro da América Latina. É explícito que a esfera do trabalho não fugiria desse processo. A catástrofe metafísica é a gênese da colonialidade. Por essa razão, afirmamos que a reprodução do trabalho escravo no século XXI está ligada diretamente a esse contexto. Como mostrado nas reflexões deste texto, o trabalho sempre foi usado para separar os subalternizados da elite, principalmente o manual e "pesado". É por meio dessas relações todas que podemos compreender a total indiferença quanto à realidade dos sujeitos que foram/são resgatados da condição de escravidão contemporânea. A catástrofe metafisica reproduz um verdadeiro apartheid no universo do trabalho, pois determinados sujeitos ficam, total ou parcialmente, excluídos das leis trabalhistas, que regulam a relação capital-trabalho, na modernidade.

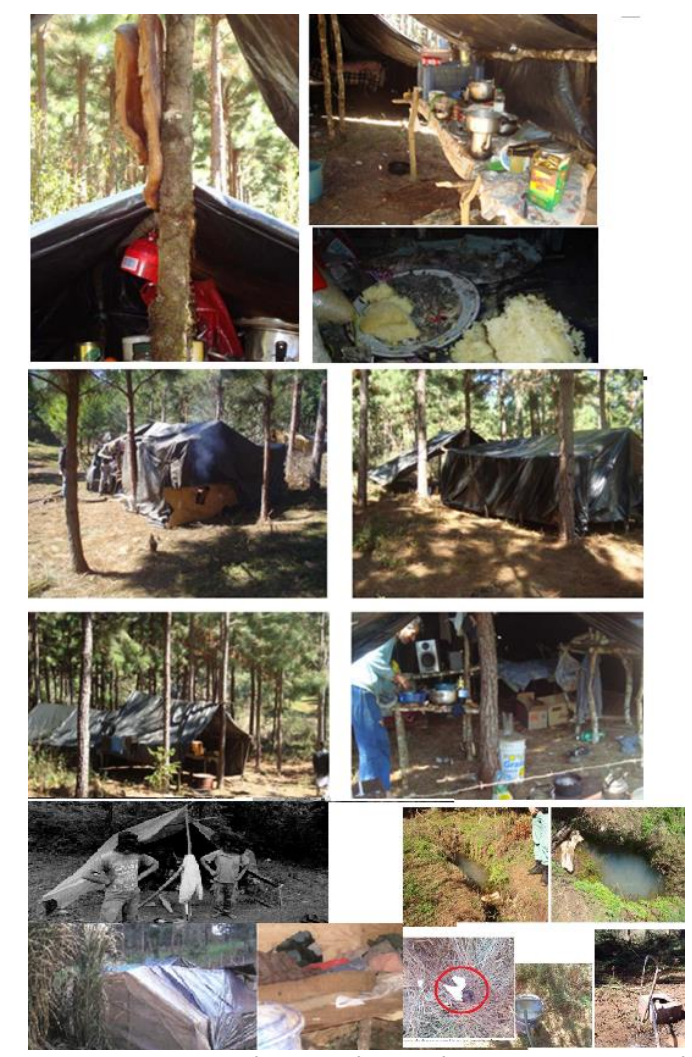

Figura 3. Condições degradantes encontradas nas

fiscalizações de combate ao trabalho escravo contemporâneo na região Centro-Sul do Paraná

Fonte: Relatórios de fiscalização GEFM (2009, 2010, 2013).

suficiência de renda gerada em suas pequenas propriedades, processo que os trabalhadores de Codó-MA chamam de "precisão e que significa necessidade financeira. Diante desse fato "se submetem às condições precárias de trabalho, mas o fazem dentro de uma lógica e de uma estratégia de complementação de renda. (Moura 2008, 177)". 
Por essa razão, a pretensão deste artigo foi provocar uma reflexão sobre o papel da colonialidade sobre o trabalho escravo contemporâneo e os motivos dela ainda perdurar. A menos que o racismo e todas as formas de hierarquização e classificação social surgidas com ele, bem como a opressão de gênero e de classe sejam extintas, o que significa uma mudança total sobre os princípios que regem e dominam a modernidade, essa violência social, usada na acumulação por espoliação do capitalismo, jamais acabará. Cabe ressaltar que os fatos narrados neste texto representam uma parte muito pequena do contexto que envolve o trabalho escravo contemporâneo no estado do Paraná.

No entanto, acreditamos que pode abrir uma via de discussão sobre as razões pelas quais ele continua a se reproduzir como eixo fundamental da engrenagem que move o sistema mundo/moderno capitalista.

\section{Considerações finais}

A pretensão deste artigo foi iniciar uma discussão sobre o trabalho escravo contemporâneo na região Centro-Sul do Paraná. Também, provocar um debate sobre como a teoria da colonialidade pode ajudar a entender a relação capital-trabalho na América Latina.

Para tanto, em um primeiro momento, mostramos o perfil dos trabalhadores e os setores econômicos envolvidos. Em seguida, iniciamos uma reflexão sobre a escravidão contemporânea na região estudada, a partir da colonialidade do trabalho, do poder e do ser. A intensão foi debater o poder da hierarquização e classificação social via trabalho e como se dava o controle e a dominação sobre os sujeitos resgatados. Nesse sentido, a principal contribuição que gostaríamos de deixar é pensar como o racismo, em suas várias manifestações, é um mecanismo privilegiado de poder, tanto na definição dos sujeitos explorados, quanto nas atividades envolvidas. Se, no período colonial, a raça era o meio principal para acionar a escravidão, agora, junto com ela, a elite apela para desumanização do ser a partir das condições materiais de vida, da cultura, do gênero e do nível de conhecimento.

Portanto, pesquisadores da questão da escravidão contemporânea devem refletir sobre importância do poder do racismo na compreensão desse problema social que já dura, pelo menos, 520 anos, no Brasil. Dessa forma, a teoria da colonialidade tem muito a contribuir porque coloca em destaque as várias formas de dominação que surgiram a partir da colonização, as quais se somam a luta de classe "clássica" e ao patriarcado do mundo eurocêntrico. Todas formas de dominação que persistem no mundo moderno/colonial capitalista do século XXI.

\section{Bibliografía}

Arquivo Público do Paraná. 2009. Catálogo seletivo de documentos referentes aos indígenas no Paraná provincial [1853]. Paraná, Curitiba.

Bernardino-Costa, Joaze. 2012. "Migração, trabalho doméstico e afeto". Cadernospagu 39: 447-459. https://doi.org/10.1590/S0104-83332012000200016, 
Bernardino, Joaze. 2002. "Ação afirmativa e a rediscussão do mito da democracia racial no Brasil". Estudos afro-asiáticos 24(2): 247-273. https://doi.org/10.1590/S0101546 X2002000200002

Castro-Gómez, Santiago. 2005. "Ciências sociais, violência epistêmica e o problema da 'invenção do outro'". En A colonialidade do saber: eurocentrismo e ciências sociais: perspectivas latino-americanas, editado por Edgardo Lander et al., 169-186. Buenos Aries: CLACSO.

Dussel, Enrique. 1993. 1492-o encobrimento do outro: a origem do mito da modernidade. Petrópolis, RJ: Vozes, 1993.

Fanon, Frantz. 1979. Os condenados da terra. Rio de Janeiro: Civilização Brasileira, 2a . Ed. Fanon, Frantz. 2008. Pele negra, máscaras brancas. Salvador: EDUFBA.

Figueira, Ricardo Rezende. 2004. Pisando fora da própria sombra: a escravidão por dívida no Brasil contemporâneo. Editora Record.

Figueira, Ricardo Rezende; Santana, Horácio Antunes de Júnior; Prado, Adonia Antunes (Ed.). 2014. Trabalho escravo contemporâneo. Mauad Editora Ltda.

Grosfoguel, Ramón. 2011. "Racismo epistémico, islamofobia epistémica y ciencias sociales coloniales". Tabula rasa 14: 341-355. https://doi.org/10.25058/20112742.431

Grosfoguel, Ramón. “El concepto de «racismo" en Michel Foucault y Frantz Fanon: ¿teorizar desde la zona del ser o desde la zona del no-ser?". Tábula rasa 16: 79102. https://doi.org/10.25058/20112742.112

Harvey, David. 1004. Novo imperialismo. Edições Loyola.

Lima, Benedito; Surkamp, Luize. 2012. Erva-mate: erva que escraviza. Fortaleza: La Barca. Lukács, György. 2013. Para uma ontologia do ser social II. São Paulo: Boitempo.

Maldonado-Torres, Nelson. 2007."Sobre la colonialidad del ser: contribuciones al desarrollo de un concepto". En El giro decolonial. Reflexiones para una diversidad epistémica más allá del capitalismo global, editador por Santiago Castro-Gomez y Ramón Grosfoguel, 127-168, Bogotá: Siglo del Hombre Editores; Universidad Central, Instituto de Estudios Sociales Contemporáneos y Pontificia Universidad Javeriana, Instituto Pensar.

Maldonado-Torres, Nelson. 2018. "Analítica da colonialidade e da decolonialidade: algumas dimensões básica". En Decolonialidae e pensamento afrodiaspórico, editado por Joaze Berdino-Costa; Nelson Maldonado-Torres y Ramón Grosfoguel. Belo Horizonte: Autêntica Editora, l.ed. (livro digital).

Marañón-Pimentel, Boris. 2017. Una crítica descolonial del trabajo. Ciudad de México: Universidad nacional autónoma de México, instituto de investigaciones económicas.

Martins, José de Souza. 2009. Fronteira: a degradação do Outro nos confins do humano. São Paulo: Contexto.

Mignolo, Walter. D. 2017. "Colonialidade: o lado mais escuro da modernidade". Revista Brasileira de Ciências Sociais 32(94). https://doi.org/10.17666/329402/2017

Moura, Flavia A. 2008. "Escravos da precisão: economia familiar e estratégias de 
sobrevivência de trabalhadores rurais em Codó (MA)". Revista Pós Ciências Sociais $5(9 / 10)$.

Munanga, Kabengele. 2019. Rediscutindo a mestiçagem no Brasil: identidade nacional versus identidade negra. Autêntica Editora.

Observatório Digital Da Erradicação Do Trabalho Escravo E Do Tráfico De Pessoas. 2018. Perfil dos casos de trabalho escravo. [s.l.].

Disponível em: https://smartlabbr.org/trabalhoescravo. Acesso em: 02 jan. 2020.

Quijano, Aníbal. 2005. "Colonialidade do poder, eurocentrismo e América Latina". En $A$ colonialidade do saber: eurocentrismo e ciências sociais: perspectivas latino-americanas, editado por Edgardo Lander et al., 227-278. Buenos Aries: CLACSO.

Quijano, Aníbal. 2014. "El trabajo al final del siglo XX". En Cuestiones y horizontes: de la dependencia histórico-estructural a la colonialidad/descolonialidad del poder: antología esencial, editado por Aníbal Quijano. Buenos Aires: Clacso.

RADAR SIT. 2020. Painel de Informações e Estatísticas da Inspeção do Trabalho no Brasil, Brasília. Disponível em: https://sit.trabalho.gov.br/radar/. Acesso em: 02 de jan. 2020. Sakamoto, Leonardo. 2011. "Os acionistas da casa grande: A reinvenção capitalista do trabalho escravo no Brasil contemporâneo". En Olhares sobre a escravidão contemporânea: novas contribuições críticas, editado por Ricardo Rezende Figueira y Adonia Antunes Prado. EdUFMT.

Santos, Boaventura de Sousa. 2007. "Para além do pensamento abissal: das linhas globais a uma ecologia de saberes". Revista crítica de ciências sociais 78: 3-46. https://doi.org/10.1590/S0101-33002007000300004

Souza, Jessé. 2017. A elite do atraso. Rio de Janeiro: Leya.

Wallerstein, Immanuel; Quijano, Aníbal. 1992. "La americanidad como concepto, o América en el moderno sistema mundial". Revista América: 1492-1992. Trayectorias históricas y elementos del desarrollo 134: 583-591.

(C) Copyright: Adriano Makux de Paula, 2021

(C) Copyright: Scripta Nova, 2021.

Ficha bibliográfica:

MAKUX DE PAULA, Adriano. Contribuições da coloniliadade do poder, do saber, do ser e do trabalho no entendimento da escravidão contemporâneo na Região Centro-Sul do Paraná. Scripta Nova. Revista Electrónica de Geografía y Ciencias Sociales. Barcelona: Universitat de Barcelona, vol. 25, Núm. 4 (2021), p. 29-50 [ISSN: 1138-9788]

DOI: $10.1344 / \operatorname{sn} 2021.25 .33745$ 